\title{
Argumentative Patterns in the Political Domain: The Case of European Parliamentary Committees of Inquiry
}

\author{
Corina Andone ${ }^{1}$
}

Published online: 22 September 2015

(C) The Author(s) 2015. This article is published with open access at Springerlink.com

\begin{abstract}
In this paper, close attention is paid to the argumentative patterns resulting from combining pragmatic argumentation in which a recommendation is made with arguments in which the majority is invoked. I focus on such argumentative patterns as employed by European parliamentary committees of inquiry conducting inquiries into the activity of the Equitable Life Assurance Society. By incorporating legal and political insights about the activity of these parliamentary committees of inquiry into a pragma-dialectical argumentative approach, an analysis will be given of the selected argumentative pattern. This analysis will reveal which standpoints are supported by which arguments and how these arguments relate to each other to increase the acceptability of the recommendation made. In addition, the analysis will explain the arguer's argumentative choices in the pattern employed.
\end{abstract}

Keywords Appeals to the majority - Argumentative pattern · European parliamentary committees of inquiry · Pragmatic argumentation

\section{Introduction}

It has become almost a cliché nowadays to say that national, European and international institutions, whether political or otherwise, suffer from an "accountability deficit." The expression 'accountability deficit' is used to suggest that those in power do not ultimately explain and justify their actions to the public and, more

The author would like to thank Henrike Jansen en Francisca Snoeck Henkemans for their useful remarks on an earlier version of this article.

Corina Andone

C.Andone@uva.nl

1 Department of Speech Communication, Argumentation Theory and Rhetoric, University of Amsterdam, Spuistraat 134, 1012 VB Amsterdam, The Netherlands 
importantly, do not take the responsibility for the consequences of their behaviour. Various solutions have been offered to solve the existing problems related to this issue, mostly by proposing political, legal and economic instruments which allegedly lead to increased accountability and in the end to more legitimacy of the institutions concerned.

At the European level, where allegations of maladministration by various institutions are common, one proposed instrument for improvement is the establishment of committees of inquiry by the Parliament. Such committees investigate inter alia cases of administrative irregularities, omissions, abuse of power, unfairness and negligence, with a view to giving an assessment and making recommendations for remedies. In the report which is issued after all the investigations have been carried out, the members of the committees of inquiry present their findings about the activity which is being investigated and propose also a number of recommendations to various actors, such as the European Parliament, the European Commission or the Member State institution into whose activities an inquiry has been carried out. In these recommendations, a future course of action is proposed by pointing at its positive consequences and emphasizing that those consequences are embraced by the majority. For example, in order to permit citizens to lodge a complaint against a company which abused them, the committee of inquiry may recommend that 'The European Commission should create the conditions for launching a collective complaint against company $\mathrm{X}$, because this leads to fairness and non-discrimination, and fairness and non-discrimination is what the majority of the consumers want'.

The goal of this paper is to open new perspectives on the study of the arguments employed by the European parliamentary committees of inquiry by showing how a systematic analysis and thorough assessment of the quality of their arguing can provide valuable insights for an adequate understanding of the broadly perceived accountability deficit. Rather than examining how the European Parliament uses its investigative powers, a task which most obviously belongs to political and legal studies, the aim is to identify typical argumentative patterns and to analyze their form and functions. In this way, conclusions can be drawn about the fundamental role played by the argumentation in the practices at issue, and about the extent to which these committees can contribute to solving the accountability deficit.

For this purpose, close attention will be paid to the argumentative patterns resulting from combining pragmatic argumentation in which a recommendation is made with arguments in which the majority is invoked (for a definition of argumentative patterns, see van Eemeren, this issue). Such a way of arguing is typical of the practices at issue and commonly employed by the committees of inquiry. It stands to reason that the most prominent forms of arguing require our attention before an explanation can be provided of other arguments. By incorporating legal and political insights about the activity of these parliamentary committees of inquiry into a pragma-dialectical argumentative approach, an analysis will be given of the selected argumentative pattern. This analysis will reveal which standpoints are supported by which arguments and how these arguments relate to each other to increase the acceptability of the recommendation made. In addition, the analysis will explain the arguer's argumentative choices in 
the pattern employed. I will concentrate on temporary committees of inquiry ${ }^{1}$ and more particularly on the inquiry into the Crisis of the Equitable Life Assurance Society as a case in point.

\section{The Argumentation of the Parliamentary Committees of Inquiry: The Case of the Inquiry into the Crisis of the Equitable Life Assurance Society}

For the purposes of this paper, it is pertinent to take a close look at those characteristics of the temporary committees of inquiry (henceforth committees of inquiry) which may affect the argumentation which is at the centre of their activities. While referring specifically to the case in point of this paper, some observations need also to be made about the scope and mandate of the committees of inquiry and their powers and duties in general.

The institutional point of all committees of inquiry set up by the European Parliament is to investigate "alleged contraventions or maladministration in the implementation of Union law, except where the alleged facts are being examined by a court and while the case is still subject to legal proceedings" (Article 226 TFEU). This formulation suggests that the members of such a committee always begin their investigations by expressing criticism with respect to the activity of the institution being investigated. Their standpoint is at all times that There are alleged contraventions or maladministration ${ }^{2}$ in the implementation of Union Law which the institution being investigated tries to refute by advancing the opposite standpoint. The institutions under investigation always represent a body of the European Communities, a public administrative body of a Member State or persons empowered by Community law to implement that law. The word 'contravention' refers to a violation of rules (in this case EU law), while the word 'maladministration' is said to apply "if a Community institution or body fails to act in accordance with the Treaties and with the Community acts that are binding upon it, or if it fails to observe the rules and principles of law established the Court of Justice

\footnotetext{
1 According to Article 226 of the Treaty on the Functioning of the European Union (TFEU), the European Parliament has the right to establish temporary committees of inquiry designed specifically to conduct 'accountability investigations'. In addition to these temporary committees, there are temporary special committees and standing committees, which are also set up by the European Parliament (on the basis of the Rules of Procedure of the European Parliament), but these committees carry out also nonaccountability investigations. Temporary committees of inquiry are the most typical cases of accountability and for this reason they have been selected for the purpose of this research.

2 The conclusions and recommendations of the committees of inquiry constitute a quasi-legal instrument, which implies that they are used to inform the investigated institutions (in this case a Member State) of the results of their investigations without having string mechanisms to enforce their powers. The sanctions they can impose do not have a formal and legal meaning, but may refer to such weak mechanisms such as negative publicity. This is explained by the fact that committees of inquiry are political rather than judicial bodies. Although they hold certain institutions to account, it is up to national parliaments and not the European Parliament to enforce measures (see Syrier 2013: 227-249). These weak powers explain the formulation in the final conclusion regarding "alleged contraventions or maladministration in the application of Community law." This 'presumptive' formulation does justice to the current status of the committees of inquiry.
} 
and Court of First Instance" (Annual Report of the European Ombudsman for 1995, 22.04.1996, p. 8). This definition, embraced by the European Commission, includes administrative omissions and irregularities, abuse of power, unfairness, incompetence, etc.

While the scope and limits of the mandate of the parliamentary committees of inquiry make clear the investigative and hence critical nature of these types of committees, their powers and duties explain how they can bring up arguments in support of their standpoint. The first source of arguments is derived from their right to call witnesses, whether these witnesses are members of an institution or a body of the European Union or the government of a Member State or other persons, such as (former) politicians, (former) servants, or persons with specific academic or practical knowledge (Syrier 2013: 39). The second source of arguments for the committees of inquiry comes from the documents which they access during the investigations, except those which are forbidden to be made public for reasons of secrecy, national security, or Community legislation or rules (Syrier 2013: 43). The third source are fact-finding visits during which the members of the committees of inquiry gather proof. Such was the case, for instance, during the investigations into the mad-cow disease when they went to the UK in order to hear the competent authorities to be able to determine whether the proposed health measures for protecting consumers were properly implemented.

Strictly speaking, according to the formulation regarding the powers of the committees of inquiry, committees of inquiry may use the three sources-witnesses' declarations, documents and fact-finding visits - to gather their arguments, but they are not obliged to do so. Practice shows, however, that until now committees of inquiry have always made use of this possibility (Syrier 2013: 35-54). In this way, justice is done to all those involved in the case under inquiry, and more importantly from an argumentative perspective, this constrains the committees of inquiry to present arguments in support of their critical standpoint which reflect the concerns of all 'stakeholders'. The arguments support the negative position taken by the committees of inquiry, thus satisfying the heterogeneous audience to whom the arguments are directed. By advancing arguments derived from various sources, committees of inquiry may also increase their relatively weak powers, ${ }^{3}$ because they enhance the appearance of having gathered sufficient arguments which could be used to enforce political sanctions.

Let me turn to the case study of this paper, the inquiry into the contraventions of the Equitable Life Assurance Society (henceforth Equitable Life) which started in 2006. ${ }^{4}$ Equitable Life is a British life insurance company whose activity includes selling annuities, i.e. an insurance product that provides periodic payments which are guaranteed in terms of amount and payment period, sometimes even for life. In the 1950s, Equitable Life began selling Guaranteed Annuity Rates, offering a guaranteed pension for life. The Society's estimation of the life expectancy of a period of 40 years proved, however, to be wrong when the moment came to carry out the payments, because people lived longer than predicted. Therefore, the Society

\footnotetext{
${ }^{3}$ See in this regard Shackleton (1998), Harlow (2002), Syrier (2013).

${ }^{4}$ Decision of January 18, 2006 (OJ L 186, 07.07.2006, pp. 58-59).
} 
decided to pay to the newly retired people much less than agreed upon, which was challenged in court by some of the policyholders affected. After the UK House of Lords decided that Equitable Life had to make all the promised payments, the financial situation of the Society worsened and in the end they went bankrupt. Immediately after, they created a new business which did pay some money to the policy holders, but $16 \%$ less than in the initial contracts. As a result of the many petitions launched by German, Irish, UK and other non-UK policyholders, the European Parliament set up a committee of inquiry to "investigate alleged contraventions or maladministration in the application of Community law in relation to the crisis of Equitable Life, without prejudice to the jurisdiction of national or Community courts." 5

The committee of inquiry started the investigations into the financial crisis at issue by limiting the difference of opinion with Equitable Life to four key issues: (a) the investigation into alleged contraventions or maladministration in the application of Directive 92/96/EEC by the UK (the Third Life Directive on the coordination of laws, regulations and administrative provisions relating to direct life assurance); (b) the assessment of the UK regulatory regime in respect of Equitable Life; (c) the status of claims and the adequacy of remedies available to policyholders; and (d) the assessment of the Commission's monitoring of implementation. ${ }^{6}$ The corresponding critical questions addressed to the various Member States were: (a) Did you implement the Third Life Directive and if so how?; (b) How did you regulate the supervision of the implementation of the Directive?; (c) What mechanisms were available to claimants in your own country?; and (d) Did the European Commission do everything possible to monitor the implementation of the Directive? (based on Final Report: Part I).

After gathering all the arguments, the committee of inquiry draws conclusions with regard to the activity of the institution or body under investigation, in this case Equitable Life. Four main conclusions were drawn in the case at issue. The first conclusion was that the UK applied the Third Life Directive deficiently and that UK regulators and authorities did not respect its purpose (Final Report: 117). The second conclusion was that the UK had a weak regulatory environment, which allowed for the problems to go unnoticed. Moreover, the committee noticed that the development of the internal market in financial services was given priority in comparison with ensuring sufficient consumer safeguards (Final Report: 204). The third conclusion was that many policyholders in the Member States did not know what route to take to launch a complaint and obtain redress for their financial losses (Final Report: 209-210). The final conclusion was that the Commission did not monitor the application of the Third Life Directive effectively by not taking a proactive stance, but rather waiting for complaints to arrive. Also, the Commission did not monitor the application of the Directive by the national authorities (Final Report: 332).

\footnotetext{
5 Decision of January 18, 2006 (OJ L 186, 07.07.2006, pp. 58-59).

6 Final Report of the European Parliament on the crisis of the Equitable Life Assurance Society (A60203/2007, 23.05.2007, p. 11).
} 
1. There are contraventions or maladministration in the application of Community law in relation to the crisis of Equitable Life

1.1a There are contraventions or maladministration in the application of Directive 92/96/EEC by the UK

1.1a.1a The UK applied the Third Life Directive deficiently

1.1a.1b UK regulators and authorities did not respect the purpose of the

Directive

[more arguments are advanced here]

$1.1 \mathrm{~b}$ The UK regulatory regime in respect of Equitable Life was weak

1.1b.1a They allowed for problems to go unnoticed

[more arguments are advanced here]

$1.1 \mathrm{~b} .1 \mathrm{~b}$ The development of the internal market in financial services was given priority in comparison with ensuring sufficient consumer safeguards

[more arguments are advanced here]

1.1c The status of claims and the adequacy of remedies available to policyholders were problematic

1.1c.1 a Many policyholders in the Member States did not know what route to take to launch a complaint

[more arguments are advanced here]

1.1c.1b Many policyholders in the Member States did not know how to obtain redress for their financial losses

[more arguments are advanced here]

1.1d The Commission did not monitor the application of the Third Life Directive effectively

1.1d.1a The Commission did not take a proactive stance

[more arguments are advanced here]

1.1d.1b. The Commission waited for complaints to arrive

[more arguments are advanced here]

1.1d.1c The Commission did not monitor the application of the

Directive by the national authorities

[more arguments are advanced here]

Fig. 1 The argumentation employed by the committee of inquiry in the case of Equitable Life

Figure 1 gives an overview of the argumentation employed by the committee of inquiry to support its standpoint in the case of Equitable iffe $^{7}$ :

The conclusions which are drawn on the basis of the outlined argumentation serve for a number of recommendations in the last part of the report. Some of these recommendations propose a number of actions to be undertaken by the investigated body, legal insights, such as insufficient legislative quality address directly the European Commission or the European Parliament, while still others propose a line of action for the committees of inquiry themselves, for instance by suggesting a way to broaden their powers and enhance their authority. In what follows, I will concentrate on the last category of recommendations for a course of action.

\footnotetext{
7 The reconstructed standpoints and arguments are presented according to the pragma-dialectical notational system (van Eemeren 2010). A, b, c, etc. stand for coordinatively coordinated arguments. The brackets indicate unexpressed arguments.
} 


\section{Argumentative Patterns Making Use of Pragmatic Argumentation}

It has been explained that the main difference of opinion between the members of the committees of inquiry and the investigated institution, in this case Equitable Life, concerns alleged contraventions or maladministration in the application of Community law. In arguing for their negative evaluation of the activity of the investigated institution, the committees of inquiry advance different kinds of coordinatively structured arguments. The specific institutional requirements impose weighing these arguments against each other and proposing a number of recommendations in which a course of action is suggested because of its positive consequences. Doing so results in advancing a prescriptive policy statement which can only be suitably supported by pragmatic argumentation. Van Eemeren and Garssen (2013: 6-7) argue that a number of critical reactions are to be anticipated in the institutional context at issue, due to the kind of argument scheme used (pragmatic argumentation) and the outcome which is institutionally envisaged (suggesting solutions for solving the alleged contraventions). By answering such anticipated critical questions, a specific argumentative pattern arises which is activated in order to realize the institutional point (van Eemeren and Garssen 2013: 7).

In my earlier research on pragmatic argumentation in practices of political accountability (Andone 2015a), I have shown that the result of a prescriptive action is judged as positive when it is shown to be in line with 'the aggregative principle' (Ball 1995: 20). In other words, when it can be shown that carrying out action $X$ is what most people want in the circumstances at hand or is in the interest of the majority. This critical question, which committees of inquiry undoubtedly anticipate since they always investigate alleged contraventions that led many people to complain about something, imposes an argumentative pattern in which the pragmatic argumentation is supported by invoking the majority. This is not an incidental argumentative pattern, but rather typical of the way in which recommendations are made by the committees of inquiry.

In all cases, it is suggested that a certain measure is proposed, a course of action is recommended or a plan is presented as necessary because the majority wants that or is in its interest. Sometimes the majority refers to the majority of the members of the committee, in other cases the will of most Member States is invoked, while in other cases the majority of those affected by the maladministration or malfunctioning is mentioned, such as policyholders in this case. ${ }^{8}$

The argumentative pattern resulting from combining a prescriptive standpoint with an argument invoking the majority can take two forms as outlined in Fig. 2:

By invoking the majority in their recommendations, it seems that the members of the committees of inquiry make in fact an attempt at developing new policies. This idea is also suggested in a briefing of the European Parliament from February 2015 when it is specified that "although parliamentary investigative powers often borrow tools from legal proceedings, they are aimed at facilitating political rather than legal control. Parliamentary inquiries are thus not quasi-judicial fact-finding proceedings,

\footnotetext{
${ }^{8}$ For examples, see the Reports on the Inquiry into the Community Transit System (1995), the Inquiry into BSE (mad-cow disease) (1996), the Inquiry into the Equitable Life Assurance Society (2006).
} 


\section{Pattern 1}

1. Action X should be carried out

1.1 a Action $\mathrm{X}$ leads to positive consequence $\mathrm{Y}$

$1.1 \mathrm{~b}$ Positive consequence $\mathrm{Y}$ is what the majority wants/is in the majority's interest

(1.1a-1.1b) If actions of type $\mathrm{X}$ lead to positive consequences $\mathrm{Y}$ and consequence $\mathrm{Y}$ is what the majority wants/is in the majority's interests, then action $\mathrm{X}$ should be carried out

\section{Pattern 2}

1. Action X should be carried out

1.1a Action X leads to positive consequence $\mathrm{Y}$

$1.1 \mathrm{~b}$ Action $\mathrm{X}$ is what the majority wants/is in the majority's interest

(1.1a-1.1b) If actions of type $\mathrm{X}$ lead to positive consequences $\mathrm{Y}$ and action $\mathrm{X}$ is what

the majority wants/is in the majority's interest, then action $\mathrm{X}$ should be carried out

Fig. 2 Argumentative patterns combining pragmatic argumentation with an argument invoking the majority will

but rather are driven by political considerations, and seek to put an issue high on the political agenda. In this sense, the parliamentary control function is an important channel for citizens' concerns" (Briefing, p. 2, my italics).

Scholars carrying out legal research on the topic (Shackleton 1998; Syrier 2013) indeed emphasize that policymaking is at issue when they demonstrate that such committees suffer of weaknesses which they try to cover up by proposing to allocate themselves more powers and liberty of action, and also trying to propose policies with wide impact. It is therefore not surprising that their pragmatic arguments in which a course of action is recommended is always supported by an invocation of the majority. As Anderson (1979: 720) emphasizes, “[...] in any democratic polity majority will [...] is accepted as the definitive test of authority. A policy is legitimate insofar as it reflects the will of the people." Before turning to a detailed discussion of the argumentative pattern resulting from combining pragmatic argumentation with invoking the majority, I will clarify majority arguments for the purposes of this paper.

\section{Defining Appeals to the Majority ${ }^{9}$}

Despite their central role in policymaking, in argumentation studies appeals to the majority have received relatively little attention compared to other forms of arguing. In most approaches to this form of arguing the majority is invoked as grounds for accepting a proposition as true, rather than as grounds for political action. Moreover, with few exceptions (Walton 1992; van Eemeren 2010), most authors have dealt with appeals to the majority as fallacious arguments, i.e., arguments which provide inadequate evidence for the truth of the proposition in question, thus equating appeals to the majority with appeals to popular opinion or argumentum ad

\footnotetext{
9 This section is a slightly revised version of one section from Andone (2015b), to be published in French, dealing with commitments in appeals to the majority.
} 
populum. ${ }^{10}$ Godden (2008: 104), for one, who takes an epistemic approach, observes that "popular opinion is typically seen as failing to support acceptability on claims. Indeed, standard accounts classify appeals to popular opinion as fallacious."

Based on the pragma-dialectical characterization of appeals to the majority (cf. van Eemeren and Houtlosser 2008; van Eemeren 2010), ${ }^{11}$ I start from the assumption that this form of arguing, just like any other kind of argument, is in itself reasonable, but can in some circumstances become fallacious if certain soundness conditions are not fulfilled. When the latter is the case, appealing to the majority does not contribute to resolving the difference of opinion on the merits (van Eemeren 2010). By treating appeals to the majority in this way, justice is done to the fact that an arguer employing such arguments makes an attempt at resolving the difference of opinion in which he is involved on the merits, without a priori attributing to him the intention of winning the discussion at all costs. ${ }^{12}$

In agreement with political science scholars according to whom such forms of arguing are employed to give support to a policy claim of legitimacy, appeals to the majority are viewed as constituting arguments which are employed as attempts to justify policy prescriptions. For my own purposes I propose to define majority appeals as a form of arguing supporting the acceptability of a claim by invoking the wants, preferences, values and interests of a great number of people. After all, democracy requires policy makers to pay attention to the public, in which case one might expect that any claims would be backed up by the public's policy preference (Cook et al. 2002). By viewing appeals to the majority in this way, it becomes clear that the legitimacy of a policy claim can be increased both in quantitative terms (a great many people are invoked) and in qualitative terms (the preferences of the people are invoked, i.e., that which they find acceptable). Moreover, and most pertinent for the purposes of this paper, it becomes possible in this way to see appeals to the majority as supporting a prescriptive standpoint in which a course of action is recommended, rather than supporting a descriptive standpoint in which something is asserted as true. In what follows, I will demonstrate how appeals to the majority work in practice when they are invoked by the committees of inquiry to support recommendations for improving the activity of the Equitable Life.

\footnotetext{
${ }^{10}$ Walton (1992: 65) takes the position that "not only is the appeal to popular sentiment or opinion of the type associated with the traditional argumentum ad populum a non-fallacious kind of argumentation in some contexts of dialogue, it is a legitimate technique and can be an important part of a constructing a successful argument."

11 A detailed account of the various forms and characteristics of appeals to the majority as discussed in the literature (Toulmin et al. 1984; Minot 1981; Walton 1992, 1999; Govier 2005; Godden 2008; van Eemeren and Houtlosser 2008) is provided in Andone (2015b).

12 Godden (2008: 102) observes that "typically, that a claim is common knowledge is taken as grounds for its acceptability, whereas appeals to popular opinion are seen as fallacious attempts to support a claim."
} 


\section{Argumentative Patterns at Work}

I have explained that pragmatic argumentation is instrumental in realizing the institutional point of the exchanges between committees of inquiry and Equitable Life, because it is a suitable means for making recommendations for solving alleged contraventions or maladministration. In turn, pragmatic arguments are typically supported by majoritarian arguments which are intended to make the proposed recommendations more legitimate. In what follows, I will describe how such a pattern manifests itself in practice and explain the argumentative choices made by the arguer. It goes without saying that in this paper I can only give a few examples to illustrate the argumentative pattern which is central to my preoccupations. In the first example, an implicit reference to the wants and interests of the majority is made which follows pattern 1 outlined in Sect. 3, in the second example pattern 2 is illustrated.

Before embarking on the analysis of the two examples, it is good to bear in mind that the Final Report of the committee of inquiry from which the examples have been taken emphasizes several times the so-called 'PRE-principle' in which the abbreviation refers to the 'policyholders' reasonable expectations.' The Report makes repeatedly clear that the proposed recommendations for a course of action are motivated at all times by the wants, interests and preferences of the majority of the complainant policyholders. It should be borne in mind that the committees of inquiry are not legal bodies but political bodies. It is therefore vital for them to take into account the majority wants and interests in a certain case. The PRE-principle is extremely important in this context, because it supports my reconstruction of the majority arguments in the two examples.

The first example is taken from Part A of the Final Report of the committee of inquiry titled Recommendations, Part II and III-Transposition and regulatory system. ${ }^{13}$ In this part, a number of recommendations are made to further strengthen the supervisory and regulatory standards throughout the Union, improve financial services legislation, and implement mechanisms which guarantee cooperation between national regulatory authorities. The example selected for this paper is the pre-final recommendation of a series of nine:

Example (1) The committee strongly requests that any financial services legislation duly recognises the priority of consumer and investor protection issues, while at the same time ensuring a dynamic and competitive environment for financial services providers that minimises red tape and does not stifle commercial flexibility and innovation. In this regard, the committee supports the emphasis on risk and principles-based regulation in financial services legislation. Furthermore, as investments in pension products are to play an increasingly important role in the European economy in view of demographic imbalance and ageing populations, the committee emphasises the need to foster consumer confidence in pension products by ensuring for them the highest standards of information, security and investor protection throughout the internal market.

\footnotetext{
13 All recommendations are made in the Final Report in 'Part VII-Recommendations of the report of the Committee of Inquiry into the crisis of the Equitable Life Assurance Society'.
} 
This example illustrates the case in which the members of the committee of inquiry propose solutions to one of the four key issues of their difference of opinion with Equitable Life concerning the UK transposition and regulatory regime. After concluding that the UK authorities did not transpose, apply and implement the EU law appropriately, the members of the committees of inquiry make two recommendations. First, they require more emphasis on principles-based regulation in any future financial legislation and second, they recommend ensuring the highest standards of security and investor protection for pension products throughout the Internal Market. As is to be expected in this context, the committee of inquiry argues for the acceptability of the two recommended courses of action by referring to the positive consequences of the proposed policies. By following the first recommendation, two positive consequences are envisaged which complement each other: (a) priority is given to investor protection issues and (b) a dynamic and competitive environment for financial services providers is ensured. By following the second recommendation, it is argued, consumer confidence in pension products will rise.

The selection of these argumentative moves is obviously not random, but can be explained in view of the institutional background against which the discussion takes place. A closer look at the institutional powers and scope of this committee of inquiry reveals that it was set up as a result of the many petitions coming from the policyholders to investigate their problems and propose solutions to these problems. Therefore, it is to be expected that in its investigations the committee pays inter alia close attention to the majority of the complainants, the more so as the complainants are also presented with the Final Report and will be interested in particular in knowing which measures are proposed to protect them. ${ }^{14}$

Having this background in mind justifies the reconstruction of at least two implicit arguments which explain the two recommendations. In the case of the first recommendation concerning principles-based regulation in any future financial legislation, the two positive consequences make sense only if an implicit reference to the wants and interests of the majority of the policyholders is reconstructed. The majority of policyholders complained that they were not fully protected, which explains the necessity to make the investor protection issue a priority. In addition, the policyholders complained about the bureaucracy which they had to face, which explains the need for a dynamic environment for financial services providers. The two favourable consequences are related in a coordinative argumentation structure. Because the arguers anticipate a criticism regarding the insufficiency of the first consequence, they mention a second consequence which is meant to take away possible doubts of more policyholders. While some of them may find it important to be protected, others may find it important to deal with less bureaucracy. In addition to the consumers, the other interested party to whom reference is made here are the financial services providers. The concept of principles-based regulation has been

\footnotetext{
14 It goes without saying that there may be other reasons why the committees of inquiry propose certain courses of action at the European level. They propose a certain measure not only because it takes into account the majority's wants and interests, but also because they would like, for instance, to support the internal market. I do not claim that the prescriptive standpoints reconstructed here are supported only by majoritarian arguments, but such arguments do play an important role as justified in the reconstruction.
} 
Recommendation 1

1. There should be more emphasis on risk and principles-based regulation in any future financial legislation

1.1a This leads to giving priority to consumer and investor protection issues

(1.1b) Giving priority to investor protection issues is in the interest of most policyholders and financial services providers

$1.1 \mathrm{c}$ This leads to ensuring a dynamic and competitive environment for financial services providers

1.1c.1a It minimizes red tape

$1.1 \mathrm{c} .1 \mathrm{~b}$ It does not stifle innovation

(1.1.d) Less red tape and innovation is what most policyholders and financial services providers want

Recommendation 2

2. The highest standards of security and investor protection throughout the Internal Market should be ensured

2.1a This leads to consumer confidence in pension products

(2.1b) This is also in the interest of financial services providers

(2.1c) Confidence in pension products is what most potential consumers and financial services providers want

Fig. 3 The argumentative patterns in example (1)

developed together with Treating the Customers Fairly (TCF) initiative, according to which "it is important to consider the benefits and opportunities that are presented to regulators, regulated entities and consumers and how a more Principles-based approach might assist in achieving the FSA's [Financial Services Authority] statutory objectives (Black et al. 2007: 191).

In the case of the second recommendation regarding standards of security and investor protection, there is an implicit argument invoking the wants of the majority of European citizens and financial services providers. This time the implicit reference concerns potential policyholders who, in light of the current economic situation in Europe, might be interested in buying pension products. Apparently, in this case only one positive consequence suffices to convince the possible policyholders. $^{15}$

Figure 3 outlines the argumentative pattern that is at issue in the two recommendations, both of which illustrate pattern 1 outlined in Sect. 3:

The arguers could have chosen to make only one recommendation. Taking into account the wants and preferences of the current policyholders could do for this inquiry. The second recommendation, which is based on an implicit reference to the potential policyholders, seems to be unnecessary. After all, the existence of a committee of inquiry and their recommendations is generally not known outside Brussels and Strasbourg. Apart from very few exceptions, such as the mad-cow

\footnotetext{
${ }^{15}$ In investigating the UK transposition and regulatory regime, the committee of inquiry refers explicitly to having investigated whether the UK authorities protected policyholders and also potential policyholders.
} 
disease crisis in the 90s, the European citizens have not heard of the activity of these committees (Syrier 2013: 238). It is quite unlikely that other people than the affected policyholders will read the Final Report.

By proposing a measure from which future policyholders may benefit could be explained by two reasons. One reason is the fact that such committees, although they were set up to examine relatively limited domains, would like to gain more powers by playing a role in policymaking with a broader impact, such as the common agricultural policy in the case of the mad-cow disease or consumer protection in the life insurance sector in the case of Equitable Life (Shackleton 1998: 125). This idea is supported by the evidence provided by legal scholars (Syrier 2013) who show that the committees of inquiry try to compensate for their fairly weak powers by not only investigating ex post actions but also making ex ante recommendations intended to prevent future problems. The second reason to refer to potential policyholders, more important from an argumentative perspective, concerns the fact that the committee anticipates a critical question in this regard and therefore seeks to answer the potential criticism. The expectation arises from their obligation to show that they proposed adequate measures "which pay due regard to the reasonable expectations of policyholders and potential policyholders" (Final Report: Comments on UK Transposition).

Example (2) The committee [...] considers that the imperatives of fairness and non-discrimination between policyholders and the prohibitive cost of legal action for the vast majority of them render it necessary to grant consumers of financial services the right under Community law to pool their resources and act collectively against providers or Member States supervisory authorities before national courts. Such a procedure, which consolidates smaller claims into one action, has the advantage of saving time and money $[\ldots]$.

This example is taken from Part B of the Final Report of the committee of inquiry titled Recommendations, Part IV-Remedies. In this part, a number of recommendations are made with regard to the remedies that could be enforced by the UK to compensate the policyholders for damages suffered under the Equitable Life crisis. This recommendation seeks to offer a solution regarding the issue of the status of claims and the adequacy of remedies available to policyholders about which there is a difference of opinion with Equitable Life. Just like in the previous case, the committee of inquiry argues for the proposed measure by pointing at its positive consequences, which are apparently in the interest of the vast majority of policyholders. In this case, the argument in which the majority is invoked is further supported by another argument which reinforces the interests of the majority.

Figure 4 outlines the reconstructed argumentation following pattern 2 explained in Sect. 3:

The members of the committee of inquiry apparently anticipate doubt with respect to the argument in which the majority is invoked. Critical questions could be raised whether it is indeed in the interest of the majority of policyholders to implement collective action, as this has its own disadvantages, such as the risk of getting the same compensation as other policyholders although you suffered more damages or the possibility of not getting enough representation in the complaint. To 
1. Consumers of financial services should be granted the right under Community law to pool their resources and act collectively against providers or Member States supervisory authorities before national courts 1.1a This leads to fairness and non-discrimination between policyholders (1.1b) Having the right under Community law to pool their resources and act collectively is in the interest of the vast majority of policyholders

$1.1 \mathrm{~b} 1$ The vast majority would otherwise not be able to afford undertaking legal action

Fig. 4 The argumentative pattern in example (2)

meet such critical questions, the committee chooses to refer to saving time and money which are explicitly presented as advantageous of a collective action. In this way, possible critical questions regarding the advantage of these apparent gains are explicitly answered.

\section{Results and Challenges}

This paper provides insights into the study of a stereotypical argumentative pattern that is commonly employed by the members of committees of inquiry of the European Parliament when they make a recommendation for a course of action. The investigated argumentative pattern consists of a prescriptive standpoint advocating a certain measure or plan for which one or more arguments are advanced which point at the positive consequences of the recommendation. In addition, the wants and preferences of the majority are invoked in order to complement the envisaged positive consequences.

The institutional preconditions prevailing in the discussions of the committees of inquiry with an institution or body criticized for alleged contravention or maladministration in the application of EU law explain the argumentative pattern at issue. These preconditions allow also for an explanation of the way in which the argumentative pattern at hand manifests itself in the discourse. To account for this, the Equitable Life Society crisis has been chosen as a case in point.

After a detailed account of the difference of opinion initiating the discussion between the parliamentary committee of inquiry and Equitable Life, and of the main arguments that play a role in the exchange, two examples have been analysed in which references to the wants, interests and preferences of the majority are closely examined. In each case, the argumentative pattern resulting from combining a pragmatic argument with arguments invoking the majority is the central concern. The first example demonstrates the necessity of accounting for the majority of people currently affected by the financial situation created by Equitable Life, as well as for the majority of those possibly affected. The second example illustrates a case in which the majority argument is further supported by another argument reinforcing its legitimacy.

These results raise at least three challenges. The first challenge concerns the evaluation of the argumentative patterns that have been examined in this paper. The 
question is whether these patterns are fallacious or not. To be able to establish this, contextualized criteria need to be developed that could be applied to distinguish systematically and confidently between reasonable and unreasonable cases. These criteria need to be developed both for the pragmatic argumentation and the majority arguments which are employed to support the main argument. The second challenge touches upon the generalizability of the observations made in this paper for the case of Equitable Life. More qualitative and quantitative research is required to study a representative corpus of examples in which more complex argumentative patterns are employed to argue for a course of action and in which appeals to the majority are complemented by further argumentation. The third challenge is to determine the possible effectiveness of the various patterns that may arise from combining pragmatic argumentation with an appeal to the majority will. For each case, an explanation is needed of the way in which the prescriptive standpoint is effectively supported by the pragmatic argument emphasizing the positive consequences of following a course of action and also by the appeal to the majority in which both a quantitative component (a large number of people) and a qualitative component (the wants and preferences of a large number of people) play a role.

Open Access This article is distributed under the terms of the Creative Commons Attribution 4.0 International License (http://creativecommons.org/licenses/by/4.0/), which permits unrestricted use, distribution, and reproduction in any medium, provided you give appropriate credit to the original author(s) and the source, provide a link to the Creative Commons license, and indicate if changes were made.

\section{References}

Anderson, Ch. 1979. The place of principles in policy analysis. The American Political Science Review 73(3): 711-723.

Andone, C. 2015a. Pragmatic argumentation in European practices of political accountability. Argumentation 29: 1-18.

Andone, C. 2015b, in press. Engagement et non-engagement dans les appels à la majorité par des hommes politiques. Argumentation et analyse du discours 16.

Ball, W.J. 1995. A pragmatic framework for the evaluation of policy arguments. Policy Studies Review 14(1/2): 3-24.

Black, J., M. Hopper, and C. Band. 2007. Making a success of principles-based regulation. Law and Financial Markets Review 5: 191-206.

Cook, F.L., J. Barabas, and I.B. Page. 2002. Invoking public opinion: Policy elites and social security. Public Opinion Quarterly 66: 235-264.

European Ombudsman. 1996. Annual Report for 1995 (22.04.1996).

European Parliament. 2007. Final Report of the European Parliament on the crisis of the Equitable Life Assurance Society (A6-02032007, 23.05.2007).

Godden, D.M. 2008. On common knowledge and ad populum: Acceptance as grounds for acceptability. Philosophy and Rhetoric 41(2): 101-129.

Govier, T. 2005. A practical study of argument. Toronto: Thomson/Wadsworth.

Harlow, C. 2002. Accountability in the European Union. Oxford: Oxford University.

Minot, W. 1981. A rhetorical view of fallacies: Ad hominem and ad populum. Rhetoric Society Quarterly 11(4): 222-235.

Shackleton, M. 1998. The European parliament's new committees of inquiry: Tiger or paper tiger? Journal of Common Market Studies 36(1): 115-130.

Syrier, C. 2013. The investigative function of the European parliament. Holding the EU executive to account by conducting investigations. Oisterwijk: Wolf Legal Publishers. 
Toulmin, S., R.D. Rieke, and A. Janik. 1984. An introduction to reasoning. Macmillan: University of California.

van Eemeren, F.H. 2010. Strategic maneuvering in argumentative discourse. Extending the pragmadialectical theory of argumentation. Amsterdam, Philadelphia: John Benjamins.

van Eemeren, F.H. 2015. Identifying argumentative patterns: A vital step in the development of pragmadialectics. Argumentation: this issue.

van Eemeren, F.H., and B.J. Garssen. 2013. Argumentative patterns in discourse. In Virtues of argumentation: Proceedings of the 10th International Conference of the Ontario Society for the Study of Argumentation (OSSA), May 22-26, 2013, ed. D. Mohammed, and M. Lewinski, 1-15. Windsor, ON: OSSA.

van Eemeren, F.H., and P. Houtlosser. 2008. Rhetoric in a dialectical framework: Fallacies as derailments of strategic maneuvering. In Dialogue and rhetoric, ed. E. Weigand, 133-152. Amsterdam/ Philadelphia: John Benjamins.

Walton, D. 1992. The place of emotion in argument. University Park: Pennsylvania State University Press.

Walton, D. 1999. Appeal to popular opinion. University Park: Pennsylvania State University Press. 